\title{
CHUVAS DE GRANIZO E DESASTRE NOS POMARES DE MAÇÃ CATARINENSES: PRODUZINDO UMA AGRICULTURA DE RISCO
}

\author{
HAILSTORMS, AND DISASTER IN APPLE ORCHARDS \\ OF SANTA CATARINA STATE: PRODUCING A RISKY \\ AGRICULTURE
}

Jó Klanovicz*

\begin{abstract}
Resumo: Este artigo discute a expansão de pomares de macieira no estado de Santa Catarina, Brasil e a relação que essa expansão teve com o risco das chuvas de granizo desde os anos 1960. O granizo foi, então, construído como desastre nos registros científicos e não científicos ligados à pomicultura da região. Para interpretar como o granizo passou a ser um dos principais agentes na construção da história da pomicultura no Brasil, foram utilizados documentos técnicos e escritas criativas, documentos históricos e relatos sobre chuvas de granizo, além de produção acadêmica recente sobre esse fenômeno climático. A discussão levou em conta o emergente campo de pesquisa que aproxima história ambiental e desastres.
\end{abstract}

Palavras-chaves: História Ambiental. Desastre. Chuvas de granizo. Pomicultura.

\begin{abstract}
This article discusses the expansion of apple orchards in Santa Catarina State, Brazil, and the relationship between this expansion of orchards and hailstorms since the 1960s. The hail was built as a disaster in scientific and non-scientific records related to pomiculture in Santa Catarina. To interpret how hailstorms became a major player in the construction of the history of pomiculture in Brazil, I used technical documents, creative writings, historical

* Professor no Programa de Pós-Graduação em História e Regiões da Universidade Estadual do Centro-Oeste (UNICENTRO PR), no Programa de Pós-Graduação Interdisciplinar em Desenvolvimento Comunitário da mesma instituição e no Departamento de História da UNICENTRO. E-mail: klanov@gmail.com
\end{abstract}


documents and ordinary accounts on hailstorms, as well as recent academic production on this climatic phenomenon. The discussion took into account the emerging field of research of Environmental History, and Disasters.

Keywords: Environmental History. Disaster. Hailstorms. pomiculture.

Entre os primeiros anos da década de 1960 e 2006, um pomar experimental de frutas de clima temperado transformou-se em mais de 7.200 hectares de macieiras no município de Fraiburgo, meio-oeste de Santa Catarina. Diversas obras de história local e regional e vários trabalhos de orientação econômica e política exaltaram o empreendedorismo e a tecnologia como elementos cruciais para o sucesso da pomicultura na região, convertendo Fraiburgo de uma vila de trabalhadores de serraria em um importante polo de atração de mão de obra especializada na fruticultura, além de uma cidade que passou a organizar sua economia, sua vida social, cultural e política em torno de uma única fruta, a maçã. ${ }^{1}$

Durante quase quarenta anos, o trabalho de transformação das paisagens, florestas ou campos, em pomares de macieira, com consequências ecológicas importantes, foi comemorado como elemento crucial para converter o território de Fraiburgo, primeiro, em "verdadeiro campo de experimentação agrícola", depois, em "espaço gerador de progresso" e, por fim, local de intensa experimentação ambiental, especialmente quando falamos em estratégias de controle da paisagem, inclusive da atmosfera. Como resultado, uma autora de história local observou, entusiasticamente, em 1984, que Fraiburgo era uma "esmeralda" no planalto de Santa Catarina, no qual os pomares contribuíram para a "expansão do verde" e do equilíbrio ecológico. ${ }^{2}$ Pouco adiante, na mesma obra, a autora enfatiza que, em 1984, tudo estava perfeito no que dizia respeito à pomicultura, com exceção do grande perigo: o granizo. Essas observações transformavam a pomicultura em base do desenvolvimento socioeconômico, político e cultural na região, mas também nos remetem à instabilidade de uma agricultura em larga escala, que, apesar de toda a tecnologia empregada, convive com problemas de ordem "natural", como chuvas de granizo ou geadas tardias. Ao tecerem verdadeiras apologias ao empreendedorismo imigrante e migrante e ao clima "europeu" ou melhor, "europeizado" da localidade, essas narrativas sobre a pomicultura, mesmo pontuando alguns problemas climáticos e intempéries, deixaram-no em segundo plano, no campo das promessas de solução tecnológica, que constituíam materialmente incertezas subjacentes à atividade. Essas tensões no discurso de sucesso, fragmentariamente foram registradas sob as mais variadas formas.

O clima e as condições meteorológicas regionais, a partir da implantação de pomares, tornaram-se fatores de risco, ainda mais que o meio-oeste de Santa Catarina é um dos locais de maior incidência de granizo na América do Sul, devido à continentalidade, à latitude. 
Percorrer o processo de transformação dos ecossistemas locais de Fraiburgo em nome da agricultura convencional moderna em regime de plantation remete-nos, portanto, a perguntas sobre a qualidade, a oportunidade, a propriedade e a operacionalização de medidas tomadas por agentes modernizadores da agricultura no sentido de identificar, mitigar, controlar e prever a ocorrência de riscos, especialmente do granizo.

Neste artigo, argumento que, nos sucessivos encontros de humanos e não-humanos na superfície dos pomares de macieira, que refletem relações entre a agricultura e política, tecnologia de força bruta e biologia, alguns personagens são fundamentais para discutir a construção histórica das práticas agrícolas, especialmente em Fraiburgo, e um deles tem sido o granizo. Neste artigo, pretendo pontuar o percurso de uma agricultura promissora, por um lado, porém acompanhada do risco imanente a qualquer agricultura de larga escala, especialmente aquele ditado por intempéries. A construção da pomicultura em regime de plantation aconteceu para o risco do granizo e da geada tardia, e vice-versa. A decisão técnica tomada a favor das grandes áreas de plantio em lugar de pequenos e esparsos pomares, debatida ainda no final dos anos 1960 por alguns agrônomos da região, significou, por conseguinte, o alargamento das condições espaciais de incidência do granizo, e essa decisão fora plenamente consciente, acalentada pela crença na tecnologia como elemento fundamental para a resolução desse problema. O granizo e o combate ao granizo alimentaram o debate e as ações de técnicos e produtores no sentido de promover ainda mais a crença na tecnologia. Dessa forma, organizo o artigo levando em consideração, preliminarmente, o debate que tem sido efetuado na historiografia sobre o tema dos desastres, para depois direcionar a atenção sobre o caso do granizo e da geada tardia na região em foco.

\section{DESASTRES E HISTÓRIA AMBIENTAL}

Diversos estudos tem servido para registrar, sistematizar e problematizar conceitual e tecnicamente a ocorrência de desastres nos campos da Geografia, da Química e da Climatologia e Antropologia. ${ }^{3}$ Mais recentemente, com as políticas nacionais brasileiras de reforço do papel da defesa civil, bem como o fortalecimento da história ambiental no país, estudos históricos começaram a participar do debate sobre a questão de riscos e desastres, sob diversas nuances, com implicações positivas do ponto de vista institucional e científico.

Lise Sedrez tem discutido comparativamente, os papéis interconectados da memória, da história e das enchentes nas cidades de Buenos Aires, Argentina, e Rio de Janeiro, Brasil, ao longo do século 20, perfazendo uma renovada análise de história ambiental urbana, especialmente do tema das enchentes. ${ }^{4}$ Outro ponto de leitura tem sido os eventos extremos na região sul do Brasil, 
que é uma das áreas de maior incidência mundial de tornados, mas também de chuvas de granizo, além de o Rio Grande do Sul ser caracterizado como um dos estados mais atingidos por estiagens históricas no Brasil, e de Santa Catarina ser marcadamente o palco de enchentes e outros eventos desastrosos de repercussão nacional e internacional. Nesse sentido, Marcos A. Espíndola tem discutido, sob o ponto de vista da história ambiental, a estiagem no oeste de Santa Catarina. ${ }^{5} \mathrm{O}$ mesmo autor, em companhia de Eunice S. Nodari e Alfredo R. S. Lopes tem descrito o contexto socioambiental fundado em torno do desastre ocorrido em 2008 no Morro do Baú, no Vale do Itajaí, em Santa Catarina, buscando perceber e avaliar políticas públicas de prevenção e diagnóstico de riscos naquela região. ${ }^{6}$ Alfredo R. S. Lopes tem conduzido pesquisa de doutorado sobre desastres ambientais e memória no sul do Brasil. ${ }^{7}$ Débora Ferreira, Lisangela Albino e Mario J. C. C. Freitas tem discutido a participação popular no enfrentamento de desastres. ${ }^{8}$ Jó Klanovicz tem discutido a relação entre história ambiental e desastre, do ponto de vista teórico, mas também empreendido estudos de caso. ${ }^{9}$ Em companhia com Maíra Kaminski da Fonseca ${ }^{10}$ e Elisiane Zvir ${ }^{11}$, tem trabalhado, também, a emergência da preocupação da opinião pública sobre relatos de fenômenos considerados desastrosos na região. Além disso, a constituição de grupos e linhas de pesquisa estritamente ligados ao tema, no campo da História, bem como a organização de eventos científicos sistematicamente devotados ao assunto tem favorecido a emergência de uma discussão sistematizada de história ambiental acerca dos mais variados sentidos atribuídos ao risco e ao desastre. ${ }^{12}$

A congruência das pesquisas materializa-se na preocupação em entender os desastres não apenas como fenômenos de ordem física mas como construções socioculturais, na medida em que é por meio das constelações sociais, políticas, econômicas e culturais que esses eventos podem ser transportados para esforços de categorização e racionalização científicas, que ocorrem contingencialmente, ou seja, são datadas e mutáveis. O esforço de percepção histórica sobre os desastres emergiu com força depois da Segunda Guerra Mundial, especialmente na França, onde os repertórios sobre transformação e estabilidade do tempo e do espaço eram fortes no campo historiográfico, por sua vez amplamente relacionado com a Geografia. ${ }^{13} \mathrm{Na}$ Alemanha, as pesquisas foram-se delineando em um grande campo conhecido como ciência do risco, agremiando debates interdisciplinares. Entre as tradições consolidadas sobre o desastre na história, derivam desse momento do segundo pós-guerra as leituras dos fenômenos a partir da longa duração ou, ainda, da histoire immobile, postulada por Emmanuel Le Roy Ladurie, perspectivas nas quais os desastres seriam enfocados por meio da estruturação, pela História, de grandes séries de eventos para comparação. ${ }^{14}$

Mais recentemente, emerge uma história ambiental do desastre, que, em certa medida, tem rompido com as leituras de longa duração, ilustrando processos naturais e tecnológicos e seu desenvolvimento a partir da busca 
de sua caracterização como evento peculiar, abrupto e imponderável. ${ }^{15}$ Os desastres, por assim dizer, raramente tem sido objeto de estudo em suas próprias histórias ambientais, porque os historiadores ainda se preocupam primeiro com a longa duração, conforme pontua Ursula Lehmkuhl. De acordo com a autora, "catástrofes atraem atenção apenas quando demonstram certa continuidade e consistência. Esse foco na mudança gradual, entretanto, negligencia o fato de que a natureza em si pode ter o caráter de um evento". ${ }^{16}$ No debate que se coloca recentemente, e que está detidamente voltado ao que François Dosse atualmente identificou como sendo o "retorno do acontecimento" na História ${ }^{17}$, caracterizar episodicamente o desastre significaria tecer uma operação teórica na qual a natureza pudesse vir a ser interpretada como agente de história. ${ }^{18}$

Ao longo da tecnificação da paisagem agrícola da pomicultura no sul do Brasil, os riscos ligados especialmente a intempéries vieram a se consolidar como um personagem importante no processo de elaboração das relações entre humanos e mundo natural. Nesse sentido a agência da natureza na história da implantação de pomares seria um dos elementos fundamentais para o desenvolvimento da própria paisagem agrícola nova formada por florestas homogêneas, como também da própria introdução de preocupações e ansiedades modernas tipicamente ligadas a uma economia agrícola voltada ao capital e à construção de culturas tecnificantes da política e da sociedade.

A politização dos desastres e a naturalização das práticas de mitigação estão intimamente conectadas, por conseguinte, com a construção de alguns discursos e práticas de acomodação das novas relações produtivas técnicas com a emergência da atividade agrícola regional, por sua vez ligada à modernização expressa pelos inúmeros movimentos presentes na transformação da paisagem por agentes públicos e privados, mas também pelos problemas de ordem ambiental. Construir mental e materialmente uma natureza propícia às intenções humanas modernizadoras constituiu uma primeira etapa dessa espécie de "civilização" da paisagem.

\section{À EXPANSÃo DE POMARES, A EXPANSÃO DOS RISCOS}

As regiões que vieram a se constituir como principais espaços produtores de maçã no Brasil, quais sejam, os municípios de Vacaria (nos Campos de Cima da Serra, Rio Grande do Sul), São Joaquim (Planalto Serrano de Santa Catarina) e Fraiburgo (meio-oeste catarinense) atraíram o interesse de empresários do ramo da pomicultura, especialmente devido ao grande apoio financeiro e técnico dado pelas autarquias de modernização agropecuária a partir da década de 1960 e pelo fomento à agricultura no âmbito, especialmente, do regime civilmilitar. Um outro elemento merece, contudo, ser considerado nessa atração e diz respeito a relações específicas de empatia de agentes da modernização 
para com a paisagem local no devir das transformações ambientais advindas da atividade.

Ao longo do processo de atração da pomicultura para essas localidades, um dos primeiros elementos que foram considerados tanto por empresários, quanto por técnicos, foi a descrição da paisagem local, do clima e de possíveis intempéries. Quanto à paisagem, já em relatos anteriores à década de 1960, uma orientação para a floresta como espaço de recursos para o enriquecimento privado estruturava narrativas locais. Maria Frey, esposa de René Frey, que construiu a primeira serraria de grande porte na área assim descreveu a paisagem local, em 7 de setembro de 1937:

Tornamos a descer e chegamos numa tapera, tendo como vestígio de uma antiga moradia, chorões de respeitável grossura, árvores de marmelo e um forno despencando coberto de roseiras e trepadeiras. Seguimos mais um pouco e chegamos numa clareira onde o mato afastou-se. Sentamos na sombra, recostando. Ainda ouvi René dizer: aqui vai ser a serraria, lá o pátio das toras, pela inclinação facilita levar os troncos na serra. ${ }^{19}$

A descrição, que esgueirava pela narrativa bucólica das paisagens idílicas, lembrava que aquela "tapera dominada pela praga do abandono" poderia vir a ser uma biorregião propícia ao empreendimento industrial da madeira nas décadas seguintes, e da pomicultura a partir dos anos 1960. A natureza não se nomeia, e, no processo de fabricação de discursos de apreensão e transformação das florestas locais, um deslocamento importante é operado dos anos 1930 para os anos 1960, qual seja, aquele que deixou de promover uma escrita da região em termos de florestas (interessante para as serrarias), para outro voltado ao clima local "europeu" e "frio", que poderia vir a acomodar pomares de clima temperado. ${ }^{20}$

Um novo fluxo de descrições ligadas à paisagem emergiu a partir da implantação de pomares de macieira. Parte dessas narrativas acabaram sendo sintetizadas e reunidas no Processo de Criação do Curso Técnico em Agropecuária da Escola de Segundo Grau Sedes Sapientiae, em 1973, quando avolumaram relatos oriundos de empresas agrícolas, agentes públicos e técnicos agrícolas. Um desses relatos foi escrito por Willy Frey, no qual afirmava que Fraiburgo havia se transformado em um "verdadeiro campo experimental para a fruticultura de clima temperado". Ainda de acordo com o empresário, a expansão do campo experimental para todo o município faria com que as florestas primárias e secundárias que ainda restavam após a devastação feita por serrarias desde 1937, perdessem território.

De uma natureza contemplada a partir de uma perspectiva utilitarista ligada à transformação da paisagem para fins de corte de madeira, agora ela 
era descrita sob a ótica da experimentação, tanto econômica, quanto científica. Nesse sentido, a descrição feita por Frey em 1973 corroborava as observações anteriormente tecidas pelo agrônomo francês Georges Delbard, em 1967, quando havia visitado Fraiburgo e começado a acompanhar sistematicamente o processo de produção, investindo, para isso, tempo, capital e experimentos. Fraiburgo, na opinião de Delbard, apresentava algumas limitações para a pomicultura, se comparado com a França, mas, também, vantagens, especialmente a altitude, que corrigiria os efeitos da latitude. ${ }^{21}$ Contudo, ainda era importante considerar alguns problemas como o granizo no verão, ou ainda, as práticas violentas de intervenção na paisagem, especialmente o incêndio florestal para dar lugar a pomares.

A própria presença de um pomar piloto, experimental, desde 1963, fazia com que a perspectiva de uma paisagem cientificizada viesse a dar a tônica na construção discursiva sobre o plantio de macieiras, corroborando o espaço como locus produtivo a partir de elementos como o clima frio.

Na primavera de 1973, Jorge Bleicher, extensionista da Empresa Catarinense de Pesquisa Agrícola constatava que, "no presente momento, achamos trabalhando, ininterruptamente, 14 tratores de esteira, destocando, formando áreas não produtivas em locais geradores de progresso". ${ }^{22}$ Observações sobre o clima e intempéries, no relato de Bleicher, também seriam fundamentais, o que inseria Fraiburgo no seleto e especial grupo, na visão dos técnicos, de municípios propícios à produção de maçãs, devido a invernos rigorosos.

Em sentido amplo, esse aspecto do clima já vinha sendo constitutivo de um discurso agrícola importante desde os anos 1960, não apenas incidindo sobre Fraiburgo, mas sobre outros locais, como São Joaquim. Em reportagem publicada em julho de 1961, a revista $A$ Cigarra trazia São Joaquim como matéria de capa, descrevendo-a como A Suiça Brasileira, ou um "pedacinho da Europa no Brasil" 23 , enfatizando que "as terras joaquinenses são de uma fertilidade pouco comum na imensidão territorial brasileira. Em 1950, o distrito de Urubici produziu sem qualquer sistematização de plantio e de colheita cerca de dois mil frutos por pé de maçã”. ${ }^{24}$ Em 1979, o engenheiro agrônomo japonês Kenshi Ushirozawa descreveria São Joaquim como a região mais apropriada, do ponto de vista climático, para o cultivo de macieiras no Brasil, embora o relevo não fosse tão adequado como o de Vacaria e os investimentos financeiros não fossem tão volumosos como em Fraiburgo. ${ }^{25}$

A expansão dos pomares foi, nesse sentido, diretamente proporcional aos desafios trazidos pela transformação do ecossistema local, onde muitas áreas que antes dos anos 1960 eram cobertas por Floresta Ombrófila Mista com prevalência de matas de araucária, passaram a ser cobertas por florestas homogêneas de macieira ao longo do período já mencionado. A acomodação da pomicultura em uma paisagem perturbada ecologicamente a partir do 
desmatamento e posterior florestamento deixou registros, nesse sentido, das fissuras ou tensões na imagem de empreendedorismo e sucesso econômico da cultura agrícola, especialmente reafirmadas em diferentes discursos, sensibilidades e intervenções técnicas na paisagem, ainda mais quando, do ponto de vista agrícola, sabe-se que as condições climáticas brasileiras para o cultivo de macieira, entre 1960 e 2000, não eram plenamente satisfeitas com a mera presença do frio rigoroso no inverno. Assim, em época de plena expansão de pomares, comemorada e acompanhada de perto pelo regime civilmilitar brasileiro, que buscou, incessantemente, promover uma política de autossuficiência alimentar, especialmente a partir do Programa de Fruticultura de Clima Temperado e do PRONAMA, de 1980, deixar em segundo plano as dificuldades climáticas da produção em nome de uma resolução técnica do problema pareceu ser a maneira escolhida para afirmar, justamente, a capacidade técnica da agricultura brasileira frente aos condicionantes naturais. Não seria forçoso admitir que, nessa agricultura que incessantemente fazia uso da tecnologia, comemorar a tecnificação da natureza e, por fim, a preponderância da política tecnocrata sobre as plantações seria um elemento-chave para a manutenção do apoio estatal aos projetos agrícolas, em pomares que foram batizados como, por exemplo, "Pomar Castelo Branco I", ou "Pomar Castelo Branco II". Como substrato desses discursos, a ideia de calcular os riscos do frio, da geada tardia, da neve e, principalmente, do granizo, tornavam-se fundamentais. Poderíamos postular, portanto, a dimensão política do granizo, que passou a ser nomeado, produzido, interpretado, posto em relação a outros eventos, por diversas instâncias.

Entre 1963 e 2006, a quantidade de área cultivada saltou de 40h para 7.219ha. Em síntese, a expansão dos pomares tem três tempos: um primeiro momento no qual as intervenções são mais drásticas, marcado pelo corte e incêndio de remanescentes florestais para dar lugar a pomares, entre as décadas de 1960 e 1970; um segundo momento no qual as áreas tomam espaços que já não tinham florestas, e, na década de 1980, reforçando-se na segunda metade da década, quando novas áreas de expansão acabam atingindo regiões de floresta secundária. Como consequência desse largo processo de dilatação do tamanho de pomares, bem como de dilatação de recursos financeiros e ambientais empregados nos pomares, as preocupações relativas a problemas ambientais da pomicultura, por conseguinte, vieram a se transformar em problemas que excediam a própria realidade produtora, transbordando para o todo social.

A empresa Reflorestamento Fraiburgo, REFLOR, absorvia grande parte da experiência acumulada no pomar experimental de Roger Biau quando passou a administrar a instalação de projetos de fruticultura em Fraiburgo a partir de 1967. Entre 1967 e 1970, aquela empresa instalou 10 projetos florestais com mudas de pinus e araucária, compreendendo 2.716,34ha e 3.618 .750 mudas. Além disso, aproveitando incentivos fiscais fixados pela Lei n. 5.106/66, começou a instalar projetos de fruticultura de clima temperado. ${ }^{26}$ 
O primeiro deles, conhecido como Granja Nodarisa, foi executado para a empresa Nodari S/A Comercial e Industrial, de Curitiba/PR, com 105 hectares e 120.900 mudas a serem plantadas entre 1969 e 1971, e com uma produção estimada para 1974 de cerca de $3.500 .000 \mathrm{~kg}$ de maçãs.

Em 1971 nasceu o segundo projeto da REFLOR, denominado de Granja Farroupilha, para a firma De marco Argenta S/A, de Videira/SC, com 15 hectares destinados para 15.000 mudas e com uma previsão de colheita de $450.000 \mathrm{~kg}$ de maças em 1975 .

O Projeto 3 - Granja Atlas, foi criado para a empresa Mecânica Atlas, de Videira/SC, com 10 hectares para 10 mil mudas, plantadas em 1971. Ainda nesse mesmo ano, são instalados o Projeto 4 e o Projeto 5, o primeiro sob encomenda da empresa Fischer S/A Comércio Indústria e Agricultura, da cidade do Rio de Janeiro/RJ, com 10 hectares e 10 mil mudas, e o segundo para Karl Hubert Gregg - Projeto Saga I, com 10ha e 10.000 mudas. Karl Hubert Gregg também encomendou à REFLOR o Projeto Saga II, com 11 hectares e 11 mil mudas a serem plantadas em 1972. Nesse ano também foram instaladas a Granja Nodarisa II, com 15,5ha e 15.500 macieiras, a Granja Fischer II (com 10 hectares e 10 mil pés), a Granja Aliança (pertencente à Aliança Navegações, do Rio de Janeiro, com 30 hectares e 30 mil mudas) e a Granja Freitag (do grupo homônimo de Joinville/SC, com 30 hectares e 30 mil macieiras).

Entre 1972 e 1973, um projeto ultrapassou a casa dos 30 hectares, até então planejados e instalados em Fraiburgo. Tratava-se da Fazenda Castelo Branco I, criada pela REFLOR e pela Renar Agro-Pastoril, com 141 hectares e 112.800 mudas. Em 1973 é instalada a Fazenda Castelo Branco II, de 140 hectares e 112.000 macieiras. A Nodarisa S/A também expande sua área produtiva no mesmo ano, instalando mais um pomar de 65 hectares e 65.000 mudas. A RENAR cria em 1974, a Fazenda Castelo Branco III, com mais 141 hectares e 112.800 mudas, além de um novo projeto a ser instalado em 1975, com 300 hectares e 240 mil árvores. ${ }^{27}$

Em 1975, a Agrícola Fraiburgo S/A instala mais de 100 hectares de macieira em Vacaria/RS. Os pomares da empresa fraiburguense naquele município gaúcho seriam os primeiros de uma série de outros que apareceriam formados tanto por essa mesma firma como por outros grupos de investimento a partir da década de 1980 .

Na primeira década de 1980, portanto, a situação da pomicultura era cômoda, com expansão de pomares garantida pelo uso da tecnologia, do conhecimento agronômico, suportado pela pesquisa privada e pública. 


\section{DAS PAISAGENS DA AGRONOMIA ÀS PAISAGENS DA ENGENHARIA CLIMÁTICA}

O período de expansão mostrou que a história local seria construída por meio da leitura de inscrições tecnológicas na paisagem. Uma vez consolidado o espaço de produção, o momento agora era dos fungos, ácaros, granizo e demais intempéries ditarem as reações humanas. O clima já vinha sendo motivo de interesse, positivado na fala pública e privada no sentido de construir uma identidade local ligada à pomicultura. Um vez consolidado, o frio e o granizo, também, tornaram-se objeto de debate técnico e não técnico na região.

Estava, com isso, desenhada o que podemos denominar, de paisagem de risco da pomicultura, em Fraiburgo, com um sensível deslocamento de uma paisagem "agronômica", ou seja, entendida como aquela das primeiras décadas da expansão de pomares, onde o relevo, o solo, as florestas e os campos foram altamente influenciados e perturbados por ações de modernização, e, agora, uma paisagem que voltava suas atenções à engenharia climática, o que impulsionava discursos explicativos e justificadores da implantação de pomares não apenas de um ponto de vista de conhecimento agrícola ligado à terra, mas também, de um ponto de vista climático. A atenção, em outros termos, não estava mais apenas na terra com solos, relevos e plantas "corrigidos", senão, também, na ideia de "correção" dos céus.

Voltavam à cena, a observação empírica e os discursos de correção da natureza, com atenção para outros elementos, como as intempéries. A observação e a experiência de viver em lugar de inverno rigoroso e de meses de final de ano que apresentam geadas tardias na primavera e no verão, bem como chuvas de granizo e outras intempéries fora de época serviram ao longo da primeira metade do século 20, como elementos para a identificação dessas regiões na ideia de "pequenas Europas" brasileiras. O frio seria construído, nesse sentido, como elemento poderoso que incidia sobre as populações locais ora em sentido positivo, como é o caso da reportagem apresentada por A Cigarra, que, em 1961 trouxe o município de São Joaquim/SC em matéria de capa, indicada como "a Suíça brasileira".

De fato, as décadas de 1950 e início de 1960 presenciaram temperaturas baixas recordes para Santa Catarina, com paisagens invernais que, infere-se, puderam influenciar na construção da ideia de que algumas regiões do sul do Brasil, devido ao frio, poderiam acomodar facilmente projetos econômicos novos, como a fruticultura de clima temperado. Nesses primeiros momentos de modernização agrícola intensa, Xanxerê, Santa Catarina, registrou-se $-11^{\circ} \mathrm{C}$. Um ano antes, termômetros indicaram $-14^{\circ} \mathrm{C}$ em Caçador, no meio-oeste do estado, em 6 de junho. Em 22 de julho de 1953, São Joaquim marcava $-12^{\circ} \mathrm{C}$, enquanto em Florianópolis, no mesmo dia, a mínima chegou a $-5^{\circ} \mathrm{C}$. Cuiabá, 
em Mato Grosso presenciou $4{ }^{\circ} \mathrm{C} .{ }^{28}$ Entre 20 e 22 de julho de 1957 , nevou ininterruptamente em São Joaquim, causando seu isolamento. ${ }^{29}$

$\mathrm{O}$ registro de frio tornou-se instrumento fundamental para os produtores de macieira na região de estudo e, principalmente, em Fraiburgo, devido à necessidade de se estudar estratégias de produção para uma fruta que precisa de, no mínimo, 700 horas de frio abaixo de $7,2^{\circ} \mathrm{C}$ para ter coloração, crescimento, e sabor de excelência no mercado.

$\mathrm{Na}$ outra ponta desse processo de construção técnica do clima como elemento fundamental para a produção, estava a preocupação com alguns de seus elementos, como o granizo, a geada tardia, ou a neve. Era com diversos desses elementos que Fraiburgo convivia nos anos 1980, além de armilária, de fungos diversos ou do perigo do ácaro marrom.

A Festa Estadual da Maçã, realizada em Fraiburgo, em 1986, bem como o sucesso das primeiras exportações da fruta, acompanhadas da campanha publicitária Maçã Brasileira: o pecado que deu certo, organizada por fruticultores da região naquele mesmo período davam o tom das comemorações do sucesso econômico da pomicultura fraiburguense. Em 1983, a revista Veja comemorava a superação da importação de maçã. Dizia a matéria que, no Brasil "controla-se o ambiente", corrigindo-se os erros naturais para construir pomares de qualidade. ${ }^{30}$ Em 1984, no mesmo diapasão, Gentila Porto Lopes, em Glória de Pioneiros, enfatizava que, no processo de expansão da pomicultura, quase tudo estava perfeito. Segundo ela, ainda havia "um sério inimigo a combater, persistente durante o verão: as tempestades de granizo. Seu efeito sobre uma plantação [era] simplesmente devastador. Em questão de minutos pode arrasar totalmente uma safra". ${ }^{31}$

Com a fala da referida autora, é necessário considerar que a história da pomicultura começa a reverter as visões. Gentila Lopes inaugura, também, uma série de narrativas que, cada vez mais, irão devotar espaço para tratar de intempéries e desafios para a fruticultura, no âmbito, por um lado, da construção de uma agricultura tecnificada.

Pouco tempo depois, Willy Frey, empresário do ramo da pomicultura, ex-prefeito de Fraiburgo e entusiasta da tecnologia agrícola lançou Fraiburgo: o berço da maçã brasileira, uma obra voltada ao público leigo que descrevia, em linhas gerais, o desenvolvimento da pomicultura. Willy Frey narrou, em sua obra, que a preocupação crescente com o granizo fez com que a Renar Maçãs adquirisse, em 1985, um radar de navio com abrangência de sinal de $50 \mathrm{~km}$ de diâmetro, para a identificação de possíveis nuvens de granizo, com vistas ao bombardeamento dessas por foguetes que tinham carga de iodeto de prata $(\mathrm{AgI}){ }^{32}$

O uso desses foguetes já era uma constante nos anos 1970, quando as cargas eram importadas da Suíça. Contudo, por imposição do governo militar, esse tipo de material teve sua importação proibida. Uma empresa do município 
de Quatro Barras, no Paraná, a Britanite, especializada em explosivos, começou a produzir congêneres nacionais, com um custo menor, que passaram a ser avidamente consumidos pelos fruticultores de Fraiburgo/SC.

Como se desenhava a paisagem para que houvesse, em definitivo, a inserção do controle da atmosfera por parte dos produtores? Do ponto de vista do clima, os problemas meteorológicos sempre constituíram elemento de importância na área, justamente devido às características regionais temperadas e de altitudes elevadas.

Henrique Massaru Yuri observou que "as características climáticas típicas dessas regiões beneficiam a produção e qualidade dos frutos, que demandam um longo período com baixas temperaturas para o desenvolvimento fisiológico apropriado. Contudo, essas mesmas características favorecem a ocorrência frequente de chuvas de granizo. ${ }^{33} \mathrm{O}$ granizo em Fraiburgo e na região produtora de macieiras adquiriu visibilidade acadêmica em áreas como a meteorologia, a geografia, a agronomia e, por fim, a história. ${ }^{34}$

Em 2003, Henrique Massaru Yuri apresentou dissertação de mestrado na Escola Superior de Agricultura "Luiz de Queiroz" (ESALQ), sobre a gestão do risco de granizo, especialmente a partir da constatação de que o prejuízo causado por chuvas de granizo na pomicultura constituía um dos principais problemas enfrentados pela atividade.

Henrique Yuri elaborou, nesse sentido, um levantamento de ocorrência de granizo, especialmente levando em consideração as áreas de Fraiburgo/SC e São Joaquim/SC, chegando à conclusão que as chuvas de granizo são mais intensas nessas regiões entre os meses de novembro e março, período crítico que compreende as fases de frutificação, maturação e colheita das maçãs. Assim é que o autor observou que existe uma média anual, para a safra 2000, de 38 chuvas de granizo. No período de dormência da fruta, entre abril e agosto, em média precipitam duas chuvas de granizo. A média aumenta entre os meses de setembro e outubro, orbitando entre 2-3 chuvas. Nesse período, os pomares de macieira estão florescendo, e o cuidado destina-se, especialmente, à preservação das flores na árvore para garantir a polinização e a frutificação. Na época de frutificação, de novembro a janeiro, a quantidade de chuvas de granizo evolui para uma média entre 5 e 6 no período. Por fim, entre os meses de colheita, registra-se uma média de $4-5$ chuvas. ${ }^{35}$

$\mathrm{Na}$ área de Vacaria/RS, a situação não é muito diferente, embora a quantidade de chuvas de granizo seja menor em comparação com Fraiburgo e São Joaquim. Leosane C. Bosco buscou observar os efeitos do granizo e das proteções contra granizo na área, e enfatiza que a "confederação nacional de municípios fez um levantamento de desastres naturais no Brasil, entre 2003 e 2010, e que o estado que teve mais desastres registrados no período foi o Rio Grande do Sul, [sendo que] cerca de $20 \%$ dos registros do estado referem-se a vendavais e chuvas de granizo. A autora enfatiza que a maior frequência de 
granizo é registrada nas regiões de maior altitude e continentalidade, tais como Vacaria ${ }^{36}$ Outro quadro, problematizado por Júlio Vilperte, afirma que "nos municípios do Rio Grande do Sul foram registrados, entre 1980 e 2005, 264 ocorrências de desastres relacionados ao granizo". ${ }^{37}$

Em linhas gerais, a preocupação acadêmica com a precipitação de granizo na região produtora tem relação direta com os incentivos dados pela própria Associação Brasileira de Produtores de Maçã (ABPM), bem como unidades de pesquisa estatais, mas que refletem, nesse sentido, o granizo como uma personagem fundamental para se pensar a relação entre humanos e não humanos na pomicultura regional. Isso não significa, contudo, que haja uma leitura extremamente acurada sobre esse fenômeno. Valeri M. Iliine et al afirmam que "atualmente, as observações meteorológicas de queda de granizo são registradas como fenômeno através de código sem dados qualitativos. $\mathrm{O}$ reduzido número de estações meteorológicas e a característica de forma isolada, torna difícil o registro do granizo de forma precisa". ${ }^{38}$ Nesse sentido é que o granizo solapa, como outros desastres, os garantidores da segurança, na medida em que seria uma ameaça abaixo do ponto da determinabilidade estatística. ${ }^{39}$

O historiador e geógrafo Marlon Brandt ${ }^{40}$ publicou uma nota de pesquisa sobre o processo de construção de método de detecção e prevenção do granizo em Fraiburgo, a partir da leitura das iniciativas que foram historicamente tomadas na região em termos de aquisição de aparato tecnológico para o "combate", que pode representar, em certa medida, um elemento para a melhoria das leituras sobre o granizo. Ele trabalhou a construção, por meio das empresas produtoras, de sistemas de combate ao granizo em Fraiburgo, sob o ponto de vista das tecnologias utilizadas. No artigo, o autor pontuou, com base em entrevistas e outros documentos, a trajetória de tentativas e erros dessas tecnologias, observando, ainda que superficialmente, o debate gerado sobre a qualidade do combate ao granizo em Fraiburgo, quando da substituição da importação de foguetes suíços por foguetes brasileiros, bem como a transição desse sistema para um sistema soviético implantado entre 1988 e 1989 e, por fim, o abandono daquele sistema e adoção de novos.

Grande parte das informações utilizadas por Marlon Brandt foram retiradas do livro Fraiburgo: do machado ao computador, escrito pelo agrônomo Thomas Joseph Burke. Thomas J. Burke foi o primeiro autor a tratar detidamente a questão do clima e sua interferência na condução social, política, científica e cultural da pomicultura em Fraiburgo, dedicando um capítulo daquela obra para discutir o tema, ainda em 1994.

O que Thomas J. Burke trazia à tona, na época, era uma nova dimensão da interpretação histórica sobre o controle das paisagens locais de Fraiburgo, destinadas às macieiras. Até aquele momento, a leitura sobre a pomicultura levava em conta, ainda que de um ponto de vista muitas vezes orientado para questões econômicas ou agrícolas, apenas as transformações e intervenções 
na paisagem terrestre. $\mathrm{O}$ autor, por sua vez, inaugura uma leitura mais ampla da agricultura de larga escala em Fraiburgo, considerando o clima, a meteorologia e, especialmente, o granizo e a geada tardia como elementos fundamentais do incremento da tecnificação. É claro que ele não direciona sua obra para uma crítica dos processos de identificação, previsão e combate ao granizo, descrevendo, apenas, os instrumentos técnicos, o conhecimento sobre a meteorologia usados pelos pomicultores de Fraiburgo, porque essa era a finalidade da obra.

Marlon Brandt, aproveitando os dados citados por Thomas J. Burke, pontua, então, que nos meses de maior frequência de chuvas de granizo, o corpo técnico da pomicultura de Fraiburgo desenvolveu, entre os anos 1970 e 1980, uma ótica de agricultura também voltada aos céus, que serviu para espalhar cerca de 300 bases de lançamento de foguetes entre todas as empresas produtoras e nos mais diferentes pomares plantados, que eram operadas por profissionais treinados para o lançamento de foguetes, chamados de "fogueteiros". O número de profissionais habilitados chegou a 470, e a quantidade disparada em uma safra no município variava muito, sendo que, em apenas um dia poderiam ser disparados até mil foguetes. Houve um ano, especialmente, em que o número de lançamentos chegara a 15 mil. $^{41}$

Em 1988, a Associação dos Fruticultores de Fraiburgo investiu cerca de 2,5 milhões de dólares na aquisição de um radar soviético e instalação de uma nova rede de bases de lançamento de foguetes (do modelo "Alazan-Kristall). $\mathrm{O}$ radar, do tipo que vinha funcionando na região de Mendoza, na Argentina, foi instalado por técnicos soviéticos na divisa entre os municípios de Fraiburgo e Lebon Régis, num morro com 1.170msnm, escolhido por ser o mais alto da região. Segundo T. J. Burke e de acordo com especificações técnicas do equipamento, o radar (que ainda está em atividade) tinha poder de prever chuvas num raio de $300 \mathrm{~km}$ e a formação de granizo a $100 \mathrm{~km}$. Ele orientava, via rádio, os disparos de 11 bases espalhadas estrategicamente pelos pomares, de onde eram lançados, em cada disparo, 3 foguetes, também soviéticos. ${ }^{42}$ Naquele novo sistema importado da União Soviética, cada foguete transportava $1 \mathrm{~kg}$ de carga útil, constituída de uma mistura de diversas substâncias químicas, contendo $30 \mathrm{~g}$ de iodeto de prata (cada grama representa 30 trilhões de núcleos de condensação, e são necessários 200 mil núcleos por metro cúbico de nuvem para evitar a formação de granizo de grandes dimensões). $\mathrm{O}$ iodeto de prata era então "aspergido, sublimado, a $800^{\circ} \mathrm{C}$, ao longo da parte da trajetória do foguete no interior da nuvem, por dispositivos especiais. Em média, para cada nuvem perigosa, do ponto de vista dos técnicos envolvidos na fruticultura, eram disparados 36 foguetes, sendo que para as nuvens menores, apenas nove eram suficientes. Contudo, havia nuvens que necessitavam de até 300 foguetes para serem "desarmadas".

Havia, no sistema soviético, dois tipos de foguetes, separados por tamanho. O primeiro deles era o "Alazan I", que foi apelidado pelos produtores 
locais de "Pedro", e alcançava $10.000 \mathrm{~m}$, liberando o iodeto entre $3.000 \mathrm{~m}$ e $8.000 \mathrm{~m}$. Depois de liberar a carga útil, o foguete era destruído por explosão no final de sua trajetória, evitando acidentes ao cair. O foguete de menor tamanho, o "Alazan II", conhecido como "Maria", alcançava $6.000 \mathrm{~m}$, liberando sua carga útil entre $2.000 \mathrm{~m}$ e $4.000 \mathrm{~m}$. As 11 bases de lançamento permaneciam em regime de prontidão durante 24 horas, desde o início de setembro até o fim de abril, operadas por equipes de 2 "fogueteiros", em sistema de rotação de turnos de 48 horas. Ao todo, 44 homens supervisionados formavam a equipe..$^{43}$

$\mathrm{O}$ autor afirma, ainda, que é difícil prever os gastos quando se lida com o tempo: "Na safra de 1989-90, foram lançados 1.258 foguetes, reduzindo para apenas 469 na safra seguinte, chegando a $2.353 \mathrm{em} 1994$. Mesmo operando com cerca de $75 \%$ de eficácia, devido ao seu alto custo operacional (cerca de 2 milhões e 500 mil dólares ano) o sistema foi desativado em meados de 1995".

Marlon Brandt ainda aproveita para historiar o processo de substituição dos foguetes soviéticos, por fim, por geradores de iodeto de prata instalados no solo. Esse processo deu-se a partir da criação da empresa Antigranizo Fraiburgo, uma terceirada da Associação dos Fruticultores de Fraiburgo, que acabou por aproveitar a estrutura física, o know how e parte da mão de obra especializada em meteorologia agrícola voltada aos problemas da fruticultura de clima temperado, na região. A empresa foi constituída em 2000, e, em 2004, já administrava uma rede de 120 geradores de solo, cobrindo uma área de 600 mil hectares a um custo inferior ao empregado em foguetes. ${ }^{44}$

Os interesses ainda continuavam privados, mas a abrangência do sistema de defesa antigranizo começava a escapar da área de Fraiburgo, para atingir outros municípios. Isso porque o gerador de solo precisava, para se tornar eficiente, ser instalado em regiões diversas, inclusive limítrofes do município. A expansão não pode ser esquecida: os geradores, não só o território de Fraiburgo sofria essa intervenção: Videira, Rio das Antas, Caçador, Campos Novos, Tangará, Ibian, Pinheiro Preto, Lebon Régis, Monte Carlo. 
Mapa 1 - Geradores de solo de iodeto de prata em Fraiburgo e região, sob o fundo escuro dos pomares

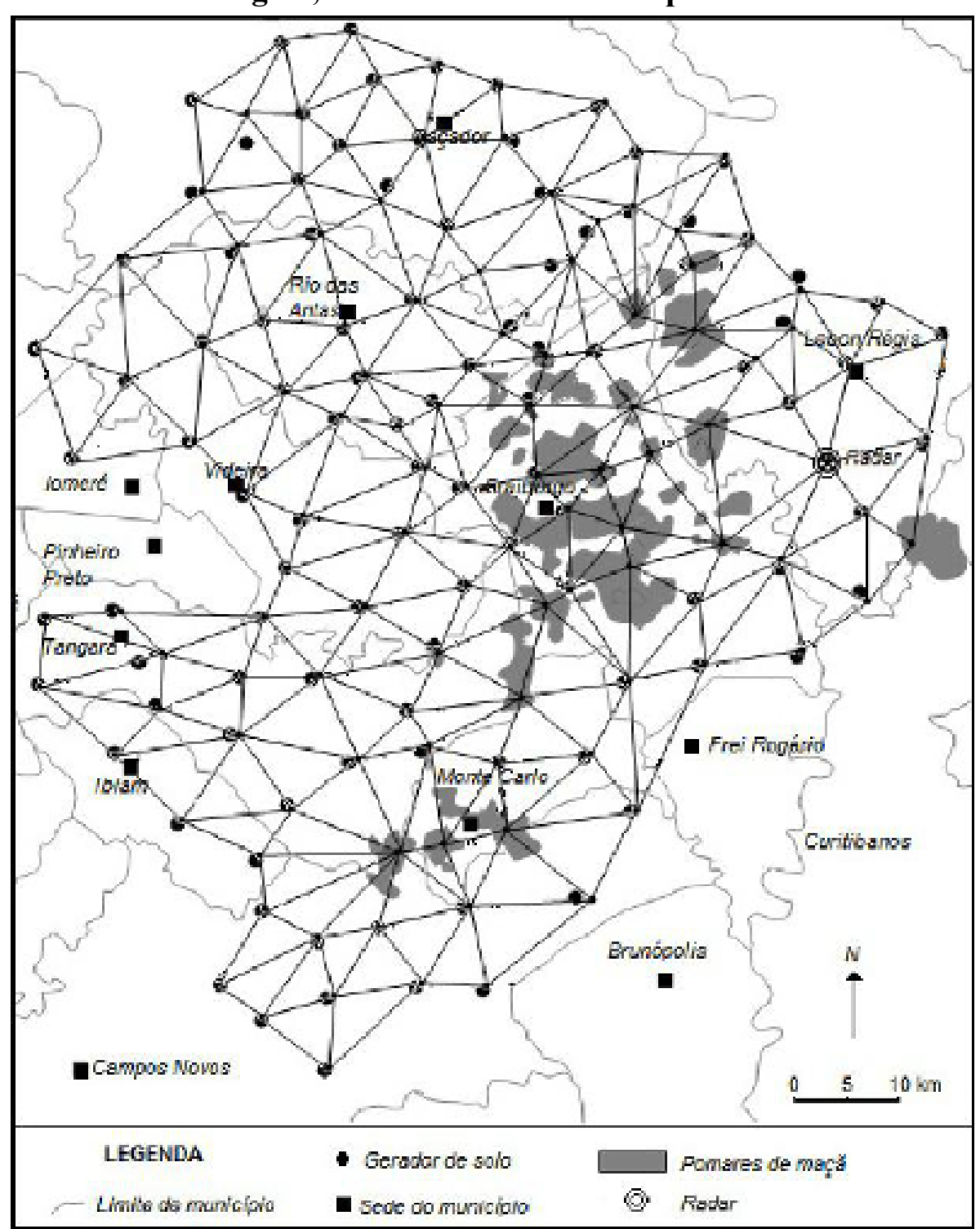

Fonte: Elaborado por Marlon Brandt, 2006.

\section{O GRANIZO NO DEBATE PÚBLICO}

Uma nova apropriação do ambiente, e do granizo como risco estava posta: uma rede de geradores de iodeto de prata instalados no solo servia para proteger especialmente a pomicultura em Fraiburgo, mas demandava, também, a instalação de geradores em outros municípios, que também pagavam os custos 
financeiros desse processo em benefício, especialmente, de Fraiburgo. Entre 1997 e 2003, esses geradores foram instalados em 218 localidades. ${ }^{45} \mathrm{O}$ mapa construído por Marlon Brandt diz mais do que apenas enfatizar a técnica de defesa contra o granizo na região produtora de maçãs do meio-oeste de Santa Catarina. Ele representa, graficamente, a expansão de um empreendimento eminentemente privado destinado, inicialmente ao cuidado dos pomares de Fraiburgo para uma zona geográfica muito mais ampla (Mapa 1).

Passados anos de dependência de Fraiburgo a sistemas de defesa contra o granizo, o problema persiste e as condições de defesa ainda são postas em dúvida. No caso de produtores de macieira, elas caminham de mãos dadas, por exemplo, com a resistência de muitos produtores, agora, em adotar os geradores de solo no município de São Joaquim. ${ }^{46}$ Contudo, a construção de Santa Catarina como espaço de desastres naturais, especialmente a partir de uma recorrente e cada vez mais intensa publicidade dada pelos meios de imprensa a eventos desastrosos, que vieram a se tornar, também, um espelho das ansiedades contemporâneas quanto a incertezas na sociedade como um todo tem redimensionado o debate em torno do granizo.

A imprensa tem sido o principal vetor de notícias sobre a ocorrência de desastres em nível regional no sul do Brasil, tanto é que as séries históricas de ocorrência de fenômenos tem feito com que pesquisadores de diferentes áreas encontrem em mecanismos como jornais ou revistas o principal foco de análise para perceber os eventos, globalmente. ${ }^{47} \mathrm{Na}$ opinião pública, contudo, com o aquecimento do debate em torno da elaboração de medidas ligadas à mitigação de desastres parece ter incrementado o discurso da húbris tecnológica nesse caso.

A húbris, ou a arrogância ou crença na certeza das estratégias, intervenções e racionalizações desse campo do conhecimento sobre a produção de alimentos, criando as condições de uma natureza industrializada, parece ter resolvido ou acobertado, em certa medida, a gênese ambígua do saber aplicado da agronomia e das técnicas agrícolas, a partir da difusão da tecnologia como forma de superação de certas barreiras biológicas ao avanço de uma agricultura de larga escala.

Essa crença, quando pensada como categoria de leitura de setores altamente tecnificados, como é o caso da pomicultura da segunda metade do século 20 no sul do Brasil, oferece um liame interessante pelo qual a agricultura convencional pode ser interpretada não apenas à luz da modernização (conservadora ou não), mas a partir de uma modernidade marcada pela capacidade humana de apropriar-se de máquinas, que, por sua vez, retroalimenta um quadro de modernismo. Nesse sentido, o viés de pensar a húbris agronômica em meio à efetiva e ostensiva transformação de paisagens agrícolas significa identificar traços de apropriação cultural da ciência e da tecnologia. Segundo Mikael Hård e Andrew Jamison, a húbris precisa ser definida como "as 
práticas discursivas, institucionais e cotidianas por meio das quais a ciência e a tecnologia são significados humanos determinados". ${ }^{48}$ Isso implica pensar os registros sobre a intervenção dos projetos de pomicultura em Fraiburgo a partir de textos ambientais nos quais é possível perceber uma orientação para a ênfase sobre a tecnologia, e sobre a sua relação com a natureza.

O debate e a crença na tecnologia de geradores de solo contra o granizo tem ocupado, também, atas de câmaras de vereadores na região meio-oeste de Santa Catarina, que tem encontrado, também, uma justificativa tecnocrática para acomodar as incertezas agrícolas. Em 8 de novembro de 2010, por exemplo, a câmara de vereadores de Tangará debateu sobre o repasse de verbas públicas para a ativação de geradores de solo naquele município, com vistas a proteger a agricultura local do granizo. Tratava-se do repasse de quatro parcelas de vinte mil reais. Ao longo da sessão, entendeu-se que o antigranizo favoreceria a população do município, e que era necessário destinar parte do orçamento anual da câmara no pagamento das ativações dos geradores.

Outros elementos ainda não tem sido debatidos no Brasil, em função da ideia de controlar o clima, quando o assunto é agricultura, com consequências socioambientais relevantes, especialmente para o caso da fruticultura de clima temperado em toda Santa Catarina, e para a pomicultura e particular. Um deles diz respeito aos efeitos do uso de iodeto de prata no combate ao granizo e os problemas advindos, para animais e plantas, da prata como metal tóxico.

Embora no Brasil não existam estudos ligados a possíveis problemas causados pelo uso do iodeto de prata em nuvens, essa preocupação tem motivado pesquisas desde, pelo menos, a década de 1970 em países como os EUA. Charles F. Cooper e William C. Jolly já pontuavam, em 1970, os efeitos nocivos do iodeto de prata em termos ecológicos, enfatizando o risco do seu uso principalmente para ambientes aquáticos. ${ }^{49}$ Há, ainda, efeitos observados sobre a germinação de plantas. Aos humanos, existe uma literatura médica que reporta casos de argiria, irritação nas mucosas nasais e garganta.

Em outros países, como na Argentina (Patagônia) e nos EUA, há, na atualidade, grupos de agricultores que tem questionado sistematicamente o uso de iodeto de prata no controle do clima, especialmente pelo volume de chuvas que essas manipulações podem ocasionar.

Outros pontos colocados por esses grupos dizem respeito a questões não apenas ligadas à saúde, mas também ao universo socioeconômico, político e cultural. Entre essas questões está aquela que nos remete a quem tem o direito de dizer que área deverá ser atendida para mitigar o granizo e que área não tem necessidade dessa mesma atenção.

O estudo do granizo e do seu combate é, também, inconclusivo em seus benefícios, e, enquanto sua manutenção é alimentada pela crença na tecnologia, não se tem observado as possíveis alterações dos ciclos naturais de água e de vapor atmosférico, por exemplo, em regiões produtoras, que carecem 
desses recursos para sua sobrevivência, com o acúmulo de mais químicos, além daqueles da agricultura da ciência agronômica, e que agora representam os novos elementos da agricultura como engenharia climática, quais sejam o iodeto de prata, o zinco ou bário.

Em 2006, outro sistema antigranizo, baseado em canhões de choques sonoros que necessitam de acetileno passou a ser discutido, especialmente pela Promotoria Pública de Vacaria, no sentido de investigar se o sistema também não estaria contribuindo para a degradação ambiental. Nesse sentido, um ciclo de audiências públicas foi organizado, para ser incluído no inquérito civil, onde figurariam, como exemplos de degradação, a falta de chuvas normais nas mesmas áreas cobertas pelo sistema. Para o promotor Luís Augusto Gonçalves Costa, o importante, das audiências, seria conciliar desenvolvimento econômico e respeito ao meio ambiente.

A discussão voltou à baila em dezembro de 2010, quando fortes tormentas de granizo causaram perdas de $65 \%$ na safra a ser colhida a partir de fevereiro de 2011, em Vacaria/RS. No mesmo ano, a quebra foi por volta de $20 \%$ em Fraiburgo/SC. As reações, porém, foram semelhantes: "o granizo é o inimigo que vem do céu", conforme observações de autoridades políticas regionais, como Francisco Appio. ${ }^{50}$

Desde setembro de 2013, audiências públicas tem sido realizadas no estado de Santa Catarina com o objetivo de discutir com a comunidade a implantação generalizada de um sistema antigranizo baseado na geração de iodeto de prata a partir do solo na região meio-oeste e oeste, com forte apelo aos agricultores e às autoridades do estado, com participação do secretário de estado da Defesa civil, Milton Hobus. A chamada para as audiências tem sido baseadas na ideia, agora, de segurança comunitária, "protegendo todo o território deste efeito climático constante na região". ${ }^{51}$

\section{CONSIDERAÇÕES FINAIS}

Há um hiato que separa a percepção de desastres e do que é desastroso ou do que apresenta risco da realidade desses fenômenos. Interpretar esses eventos, portanto, não como repetições dentro de uma série dada em longa duração e sim a partir da pontualidade de sua ocorrência permite-nos, historicamente, observar que a busca pela informação científica precisa sobre esse tipo de fenômeno muitas vezes devem ser perscrutadas via as estimativas científicas, associadas a avaliações laicas baseadas em experiências pessoais sobre esses acontecimentos, como pontua Greg Garrard. ${ }^{52}$

Assim, a construção do granizo na região de Fraiburgo como um dos principais elementos de risco para a pomicultura, como evento desastroso que excede o campo da produção agrícola para atingir as páginas de escritores de 
história regional, de atos oficiais do município, e da crença na tecnologia por parte do corpo técnico em empresas privadas e, depois, preocupação pública que motiva audiências públicas, representa um elemento fundamental nos deslocamentos pelos quais passaram as relações entre humanos e não humanos na região a partir da modernização agrícola regional com base na fruticultura de clima temperado desde os anos 1960.

Todos os dispositivos tecnológicos ligados ao combate ao granizo foram, ao longo do processo de intensa tecnificação, mantendo e sendo constituídos a partir de uma relação de negociação entre populações humanas e o clima, na qual, apesar da insistência na crença da tecnologia para a previsão, a detecção e o controle e granizo representaram registros interessantes das intenções humanas em torno de projetos econômicos e tecnológicos de "controle da natureza".

\section{NOTAS}

${ }^{1}$ As primeiras obras são: LOPES, Gentila P. Glória de pioneiros: o Vale do Rio do Peixe, 1934-1984. Curitiba: Lítero-Técnica, 1984; FREY, Willy. Fraiburgo: berço da maçã brasileira. Curitiba: Vicentina, 1989; BURKET, Thomas J. Fraiburgo: do machado ao computador. Curitiba: Vicentina, 1994.

${ }^{2}$ LOPES, Gentila P. Glória de pioneiros: o Vale do Rio do Peixe, 1934-1984. Curitiba: LíteroTécnica, 1984.

${ }^{3}$ Herrmann et al (mimeo) Herrmann et al têm discutido os desastres naturais em sentido amplo no Estado de Santa Catarina, a partir do estabelecimento, em mapa, dos pontos mais vulneráveis a esses acontecimentos. Por outro lado, há pesquisas voltadas a desastres específicos, como é o caso do trabalho de GONÇALVES, Edson F. et al. Distribuição dos desastres naturais no Estado de Santa Catarina (1980-2003), in Simpósio Brasileiro de Desastres Naturais 1, 2004. Florianópolis. Anais... Florianópolis: GEDN/UFSC, 2004. p. 773-786. (CD-ROM). O Instituto Nacional de Pesquisas Espaciais (Inpe) tem buscado sistematizar a ocorrência de desastres no Sul do Brasil por meio da reunião de documentos na imprensa online. Um mapeamento das inundações também tem sido constantemente alimentado e discutido em termos de geociências. Esse grupo tem organizado clipping diários de 38 jornais online do Paraná, do Rio Grande do Sul e de Santa Catarina, com vistas a estabelecer uma metodologia de leitura das intensidades das catástrofes que atingem a região, porém não levando em consideração as múltiplas manifestações culturais em torno desses eventos, e sim querendo estabelecer o número de vítimas, o prejuízo financeiro e as localidades atingidas segundo as narrativas encontradas.

${ }^{4}$ SEDREZ, Lise F. Urban nature in Latin America: diverse cities and shared narratives. LEAL, Claudia; PADUA, José A.; SOLURI, John (Orgs.). New environmental histories of Latin America and the Caribbean. RCC Perspectives. Munich: p. 59-66, 2013. Disponível em: $<\mathrm{http}: /$ www.environmentandsociety.org/sites/default/files/2013 i7 englisch.pdf $>$ Acesso em: $12 \mathrm{fev}$. 2014; SEDREZ, Lise. F.; MAIA, Andréa C. N. Narrativas de um Dilúvio Carioca: memória e natureza na Grande Enchente de 1966. História Oral, Rio de Janeiro, v. 2, p. 221-254, 2011.

${ }^{5}$ ESPÍNDOLA, Marcos A. Aspectos ambientais da estiagem no Oeste catarinense. Revista História Catarina, v. VII, p. 19, 2013. 
${ }^{6}$ ESPÍNDOLA, Marcos A.; NODARI, Eunice S.; LOPES, Alfredo R.S. Situação pós-desastre de 2008 no complexo do Morro do Baú, Ilhota - Vale do Itajaí: a (re)produção social do risco. CESContexto. Coimbra: CES-Universidade de Coimbra, 2013. Disponível em: $<$ http://www. ces.uc.pt/publicacoes/cescontexto/ficheiros/cescontexto_debates_i.pdf $>$ Acesso em: 12 fev. 2014.

${ }^{7}$ LOPES, Alfredo R. S. Desastres Naturais e Memória no Sul de Santa Catarina (19502010). Pesquisa de Doutorado, iniciada em 2011. Plataforma Lattes. Disponível em: $<$ http:// buscatextual.cnpq.br/buscatextual/visualizacv.do?metodo=apresentar\&id=K4711556Z7>. Acesso em: 12 fev. 2014.

${ }^{8}$ FERREIRA, Debora; ALBINO, Lisangela; FREITAS, Mario J. C. C. Participação Popular na Prevenção e Enfrentamento de Desastres Ambientais: resultados de um estudo piloto em Santa Catarina, Brasil. Revista Geográfica de America Central (online), v. 47 E, p. 1-17, 2011.

${ }^{9}$ KLANOVICZ, Jó. História ambiental e desastres: encontros entre política, tecnologia e sociedade. História Unisinos, Novo Hamburgo, v. 17, p. 293-302, 2013; KLANOVICZ, J. Apontamentos teórico-metodológicos para uma história ambiental dos "desastres naturais" em Santa Catarina. Tempos Acadêmicos, Criciúma, v. 1, p. 1-10, 2008.

${ }^{10}$ FONSECA, Maíra K. da; KLANOVICZ, Jó. Chernobyl (1986) Goiânia (1987): representação de tecnodesastres na Revista Veja. In: 22 EAIC - Encontro Anual de Iniciação Científica/3 EAITI - Encontro Anual de Iniciação Científica Tecnológica e Inovação, 2013, Foz do Iguaçu. Anais do $22^{\circ}$ EAIC/3 EAITI. Foz do Iguaçu/PR: UNIOESTE, 2013. v. 1. p.1-4; KLANOVICZ, Jó; FONSECA, Maíra K. Desastres no sul do Brasil: História Ambiental e Imprensa. In: Simpósio Internacional História Ambiental e Desastres, Guarapuava, 2011.

${ }^{11}$ ZVIR, Elisiane; KLANOVICZ, Jó. Percepções sobre a geada negra de 1975 no jornal Folha de São Paulo. In: $22^{\circ}$ EAIC - Encontro Anual de Iniciação Científica/3 EAITI - Encontro Anual de Iniciação Científica Tecnológica e Inovação, 2013, Foz do Iguaçu. Anais do $22^{\circ} \mathrm{EAIC} / 3$ EAITI. Foz do Iguaçu/PR: UNIOESTE, 2013. v. 1. p. 1-4.

12 O Programa de Pós-Graduação em História da Universidade Federal de Santa Catarina (UFSC) tem concentrado a maior parte das pesquisas ligadas à História Ambiental no sul do Brasil. Desde 2011, Eunice Nodari coordena o projeto Desastres ambientais e politicas públicas em Santa Catarina sob o viés da História Ambiental, no âmbito do Laboratório de Imigração, Migração e História Ambiental (LABIMHA). O LABIMHA também organiza o principal evento científico de História Ambiental do Brasil, o Simpósio Internacional de História Ambiental e Migrações, que tem destinado espaço contínuo ao trato da história e desastres. No Paraná, o Laboratório de História Ambiental e Gênero (LHAG) da Universidade Estadual do Centro-Oeste (UNICENTRO) estabeleceu, desde 2010, uma linha de pesquisa inteiramente voltada à história ambiental e desastres. Como resultado, já foram produzidas três pesquisas de Iniciação Científica ligadas ao tema, além de, atualmente, o Programa de Pós-Graduação em História e Regiões daquela instituição ter uma pesquisa de mestrado ligada ao desastre que ficou conhecido como o "Caso Rhodia", em Cubatão, São Paulo. O LHAG organiza o Simpósio Internacional "História Ambiental e Desastres", de dois em dois anos. A Universidade do Estado de Santa Catarina (UDESC) realiza o Workshop Internacional de História do Ambiente e Educação Ambiental, que também tem ampliado o espaço de debate sobre o tema.

${ }^{13}$ POLIDOWA, Guido. Learning from disasters. Historical Social Research. Koln, v. 37, 2007, p. 169-199.

${ }^{14}$ BANKOFF, Gregg. Comparing Vulnerabilities: Toward Charting an Historical Trajectory of Disasters. Historical Social Research/Historische Sozialforschung, 32, 3, p. 102-114, 2007. 
${ }^{15}$ Ibidem.

${ }^{16}$ LEHMKUHL, Ursula. Historicizing Nature: Time and space in German and American environmental historiography. In LEHMKUHL, Ursula; WELLENHEUTER, Helmutt. Historians and nature. New York: Ber, 2007.

${ }^{17}$ DOSSE, François. Renascimento do acontecimento. São Paulo: Editora da UNESP, 2013.

${ }^{18}$ RADKAU, Joachim. Nature and power: a global history of the environment. Cambridge: Cambridge University Press, 2008.

${ }^{19}$ LOPES, op. cit., p. 37.

${ }^{20}$ BANKOFF, Gregg. Comparing vulnerabilities, 2007, p. 103-114; LEHMKUHL, Ursula. Historicizing nature. In: LEHMKUHL, Ursula; WELLENHEUTER, Helmutt. Historians and nature. New York: Berg, 2007. p. 17-44.

${ }^{21}$ DELBARD, Georges. Jardinier du monde. Paris: Hachette, 1986. p. 504.

${ }^{22}$ BLEICHER, Jorge. Situação atual do município de Fraiburgo. In: SIMONETTI, B. Processo de Criação do Curso Técnico Agrícola da Escola de Segundo Grau Sedes Sapientiae. Fraiburgo, 1973. Datilografado.

${ }^{23}$ A CIGARRA. No sul do Brasil onde florescem as macieiras. Rio de Janeiro, n. 7, jul. 1961.

${ }^{24}$ Ibidem.

${ }^{25}$ KLANOVICZ, Gomercindo. Entrevista concedida a Jó Klanovicz. Fraiburgo: 15 fev. 2003.

${ }^{26}$ KLANOVICZ, Jó; NODARI, Eunice S. Das araucárias às macieiras: transformações da paisagem em Fraiburgo/SC. Florianópolis: Insular, 2005. As informações de expansão nos próximos parágrafos também são retiradas dessa obra.

${ }^{27}$ FREY, Willy. Declaração encaminhada à Escola de Segundo Grau Sedes Sapientiae, em 24 de setembro de 1973, descrevendo todas as instalações da empresa e liberando-as para ouso dos professores e alunos, In: SIMONETTI, Biágio (Pe.) Processo de criação do curso técnico em agropecuária da Escola de Segundo Grau Sedes Sapientiae, de Fraiburgo-SC. Encaminhado à Secretaria Estadual de Educação em 27 de setembro de 1973. Fraiburgo, 1973. [datilografado]. fl. 23-40.

${ }^{28}$ CARVALHO JUNIOR, Ilton J. de. A neve em Palmas: da reconstrução histórica à abordagem dinâmica. Rio Claro. Dissertação (Mestrado em Climatologia). Universidade Estadual Paulista. Rio Claro, 2004, p. 85.

${ }^{29}$ DIÁRIO DO PARANA. Socorrida pela base aérea de Curitiba a cidade de São Joaquim. Curitiba, 26 jul. 1957.

${ }^{30}$ KLANOVICZ, Jó. Natureza corrigida: uma história ambiental da pomicultura. Tese. Doutorado em História (Programa de Pós-Graduação em História) Universidade Federal de Santa Catarina. Florianópolis, 2007.

${ }^{31}$ LOPES, op. cit., p. 24.

${ }^{32}$ FREY, op. cit.

${ }^{33}$ YURI, Henrique M. Gestão do risco de granizo pelo seguro e outras alternativas: estudo de caso em pomares de maçã de Santa Catarina. Dissertação (Mestrado em Agronomia). Piracicaba, 2003. $141 \mathrm{p}$.

${ }^{34}$ Note-se que Santa Catarina apresenta algumas regiões, como a do meio-oeste, com alta incidência de granizo. Cf. MARCELINO, Isabela. et al. Ocorrências de granizo no estado de 
Santa Catarina. In: Simpósio Brasileiro de Desastres Naturais, 1, 2004, Florianópolis. Anais... Florianópolis: GEDN/UFSC, 2004. p. 795-805 (CD-ROM).

${ }^{35}$ FREY, op. cit., p. 51.

${ }^{36}$ BOSCO, Leosane Cristina. Alterações microclimáticas causadas por cobertura antigranizo e efeitos sobre o desenvolvimento e produção de macieiras. $203 \mathrm{f}$. Tese (Doutorado em Agronomia). Porto Alegre. UFRGS, 2011.

${ }^{37}$ VÍLPERTE, Júlio. Avaliação de perdas causadas por granizo na cultura da macieira: estudo do caso da Empresa Germano Tedesco Fruticultura, Safra 2010/11, Vacaria/RS. Monografia (Curso de Graduação em Agronomia). Florianópolis, 2011.

${ }^{38}$ ILIINE, Valeri M. et al. Climatologia da precipitação de granizo na região central do estado de Santa Catarina. Disponível em: <http://www.labclimagri.ufsc.br/granizo_cbmet10.pdf>. Acesso em: 13 mar. 2014.

${ }^{39}$ GARRARD, Greg. Ecocritca. Brasília: Editora da UnB, 2006. p. 25.

${ }^{40}$ BRANDT, Marlon. Notas sobre a detecção e prevenção do granizo nos pomares de macieira do município de Fraiburgo, SC. Estudos geográficos. Rio Claro, v. 4, n. 2, p. 83-95, dez. 2006.

${ }^{41}$ FREY, op. cit.; BURKE, Thomas J. Fraiburgo: do machado ao computador. Curitiba: Vicentina, 1994. p. 104.

${ }^{42}$ BURKE, op. cit., p.104.

${ }^{43}$ Ibidem.

${ }^{44}$ BRANDT, op. cit.

${ }^{45}$ Ibidem.

${ }^{46}$ YURI, op. cit., p. 89.

${ }^{47}$ KLANOVICZ, Jó. Apontamentos teórico-metodológicos para uma história ambiental dos desastres "naturais" em Santa Catarina. Tempos acadêmicos. Criciúma, n. 6, p. 1-10, 2008. As narrativas servem como barômetros culturais das relações entre humanos e mundo natural, que resultam, na forma de ressonância, em escritas da natureza e imaginações ambientais sobre desastres, estando, portanto, na intersecção entre humanos e mundo natural. Ver: BUELL, Lawrence. Environmental imagination. Boston: Belknap/Harvard Univrsity Press, 1995.

${ }^{48}$ HÅRD, Mikael; JAMISON, Andrew. Hubris and hybrids: a cultural history of technology and science. New York: Routledge, 2005.

${ }^{49}$ COOPER, Charles F.; JOLLY, William C. Ecological effects of silver iodide and other weather modification agents: a review. Water Resources Research. v. 6, n. 1, feb. 1970, p. 88-98.

${ }^{50}$ APPIO, Francisco. Comentário de 7 dez. 2010. Disponível em: $<$ http://www.appio.com.br/ noticias2010/not_071210.htm>. Acesso em: 13 mar. 2014.

${ }^{51}$ AUDIÊNCIAS PÚBLICAS SOBRE O ANTIGRANIZO EM SANTA CATARINA. Disponível em: $<$ http://agenciaal.alesc.sc.gov.br/index.php/gabinetes_single/deputado-renointermedia-ampliacaeo-do-sistema-antigranizo>. Acesso em: 12 fev. 2014.

${ }^{52}$ GARRARD, op. cit., p. 132.

\section{Artigo recebido em dezembro de 2013. Aceito em dezembro de 2013.}

